Article

\title{
Impact of the Universal Two-Child Policy on the Workload of Community-Based Basic Public Health Services in Zhejiang Province, China
}

\author{
Yanrong Zhao, Junfen Lin, Xiaopeng Shang, Qing Yang, Wei Wang and Yinwei Qiu * \\ Zhejiang Provincial Center for Disease Control and Prevention, Hangzhou 310051, China \\ * Correspondence: ywqiu@cdc.zj.cn; Tel.: +86-571-8711-5291
}

Received: 13 June 2019; Accepted: 6 August 2019; Published: 12 August 2019

\begin{abstract}
We aimed to quantitatively estimate the amount of pressure that was placed on basic public health care services (BPHS) due to the universal two-child policy issued in 2015 by comparing the workload change in maternal and child health management and the immunization of children. BPHS performance surveillance data from 2014 to 2018 in Zhejiang Province, China were analyzed to calculate the workload of the above three services using the equivalent method of BPHS cost estimation of community health services. From 2014 to 2018, the numbers of births from the Statistical Yearbook in Zhejiang Province were 578,000, 581,000, 624,000, 670,000, and 628,000, respectively, and those from the surveillance data were $416,941,41,490,434,163,546,816$, and 45,964 , respectively. The number of births reached a peak in 2017, with the yearbook and surveillance data showing increases of $15.92 \%$ and $31.15 \%$, respectively, over 2014. The workload of maternal and child health management and children's immunization also peaked in 2017 , increasing by $30.37 \%, 12.70 \%$, and $4.33 \%$ over 2014 , respectively. In 2018, the workload of maternal and child health management and children's immunization dropped to $107.34 \%, 107.73 \%$, and $98.81 \%$ over 2014 , respectively. The indicators of maternal and child health management and children's immunization services remained stable, and the related services did not decline, even in 2017. The maternal health management workload was more affected by the universal two-child policy than child health management and children's immunization.
\end{abstract}

Keywords: basic public health services; workload; universal two-child policy

\section{Introduction}

The negatives of the one-child policy introduced in 1979 by the Chinese government have appeared gradually and include an aging population, a skewed sex ratio, and a decline in the working-age population, which could threaten economic growth. In October 2015, China announced that the one-child policy had been replaced by a universal two-child policy, allowing all couples to give birth to two children [1-3]. Researchers predict that the universal two-child policy transition will have many benefits [1] such as a larger population size and workforce, which will help mitigate the serious aging population situation, higher consumption, and job opportunities associated with childbearing, which will contribute to economic growth. A substantial reduction in sex-selective abortions will be seen in the future, but a reduction in the sex ratio at birth is unlikely to completely normalize for many years. The undesirable trend of increasing numbers of childless families will substantially decline under the universal two-child policy due to a reduction in the bribery of officials for permission to have more than one child and a merging of family planning organizations into the National Health and Family Planning Commission [4], all of which will help to create a more harmonious society.

However, many questions remain. Although the implementation of the universal two-child policy has made numerous families reshape their decision making in terms of the mode of delivery, 
with a lower cesarean delivery rate for women who intend on having a second child [5-7], the rate of repeated cesarean delivery for women who have a cesarean delivery history is much higher [8]. Increased medical risks of pregnancy-related complications among older women have also been reported [9]. A major concern is the limited and uneven health care resources across the country, where any increase in the birth rate resulting from the universal two-child policy will exacerbate pressure on an already stressed system.

At the initial implementation stage of the policy, many studies have focused on the allocation shortage of pediatrician and maternal beds, especially in large-scale maternal and child care hospitals [10-12]. Few studies have analyzed the impact on community health services (CHSs). However, for a long period, community health service institutions including community health care centers, township hospitals, and village clinics have been designed to deliver comprehensive primary health care (PHC) services such as maternal and child health care and the immunization of children. In particular, since 2009, the Chinese government has launched health care reform for the equalization of basic public health services (BPHSs) [13,14]. A national essential public health services package was issued that included the establishment of health records, health education, immunization, child health management, maternal health management, geriatric health, hypertension and type 2 diabetes management, severe mental illness management, and the surveillance and control of infectious diseases and public health emergencies [14], which is continually being expanded. The CHSs, as the health gate keepers in a hierarchical medical system, are responsible for providing the BPHS package [13,14].

From 2014 to 2018, China's annual number of births was 16.87, 16.55, 17.86, 17.23, and 15.23 million, respectively. The number of births was higher in 2016 and 2017, while lower in 2018 when compared to 2014 and 2015 [15,16]. The dramatic change in birth rate directly affects the implementation of maternal-and child-related health services (maternal and child health management and children's immunization). With the insufficient allocation of health service resources, it is unknown as to which service was the most affected by this one shot birth boom. Will it lead to a decline in the performance of related services? Was the increase in service workload proportional to the birth increase? These questions have yet to be answered. Although when answering reporters' questions on the two-child policy, an officer of the National Health and Family Planning Commission said that the government was confident that the implementation of this two-child policy would not place considerable pressure on the public services of health care [17].

We aimed to quantitatively estimate how much pressure was placed on the BPHS due to the universal two-child policy by analyzing the BPHS surveillance data from 2014 to 2018 in Zhejiang Province, China.

\section{Materials and Methods}

\subsection{Data Source and Collection}

The birth data were obtained from the Zhejiang Statistical Yearbook and compared with the birth data from the BPHS surveillance, which was also the source of the maternal and child health management data. The surveillance system was set up in accordance with the Basic Public Health Service Standards of Zhejiang Province (4th Edition); BPHS progress data were reported by CHS institutions with integrated verification. The data of children's immunization were released by the provincial center for disease control and prevention (CDC) [18-22].

\subsection{Measures and Variables}

The workload measurement was derived from the equivalent method of the BPHS cost estimation of the CHS institutions. In the equivalent method [23], the workload indicator of a standard clinic visit (a family physician consulting with one patient for $15 \mathrm{~min}$ ) was defined as one equivalent value (EV). Equivalent values of all of the other PHC services (BPHS included) were then calculated as their workload indicators when compared with the standard clinic visit. For example, the workload 
indicator of one home visit was 60.00 person-time, so its EV was 4. The EVs of the BPHS services in Zhejiang Province were modified based on the results of Beijing-based research [23] and the related values are shown in Table 1. The volume of each service was multiplied by their EV, and then added together to produce the total workload of maternal and child health management and children's immunization services. The workload of one service $=\sum E V$ of the sub-item service multiplied by the volume of sub-item service.

Table 1. The equivalent values (EVs) of related community basic public health services (BPHS) in Zhejiang Province, China.

\begin{tabular}{|c|c|c|}
\hline Category & Sub-Item & $\mathbf{E V}$ \\
\hline \multirow{5}{*}{ Maternal health management } & Registration in early pregnancy & 8/person \\
\hline & $\begin{array}{c}\text { Prenatal examination (average } 4 \text { times per } \\
\text { person) }\end{array}$ & 1.5/person-time \\
\hline & Postpartum visit & 3/person \\
\hline & 42-day postpartum examination & $1 /$ person \\
\hline & High-risk pregnancy management & 4/person \\
\hline \multirow{5}{*}{ Child health management } & Home visit to newborn infant & 3/person \\
\hline & Health record establishment of newborn infant & $0.5 /$ person \\
\hline & Health management of children aged 0 to 2 years & 2.5/person-time \\
\hline & Health management of children aged 3 to 6 years & 2/person \\
\hline & $\begin{array}{l}\text { Health management of high-risk infants and } \\
\text { children with nutritional diseases }\end{array}$ & 2/person \\
\hline \multirow{2}{*}{ Children's Immunization } & Establishment of vaccination certificate & $0.5 /$ person \\
\hline & Vaccination & 1.5/dose \\
\hline
\end{tabular}

\subsubsection{Workload Measurement of Maternal Health Management}

The surveillance data were limited to the registration number in early pregnancy, the number of prenatal examinations, and the number of postpartum visits. To maintain a high consistency between the postpartum visited population and the 42-day postpartum examination population, the number of 42-day postpartum examinations was substituted by the number of postpartum visits. Due to the lack of related data, the workload of high-risk pregnancy management was not considered in this paper. The following formula was used to obtain the workload of maternal health management:

Workload of maternal health management $=$ registration number in early pregnancy $\times 8 /$ person + the number of prenatal examinations $\times 4$ times $\times 1.5 /$ person-time + the number of postpartum visits $\times$ (3 person-time +1 person-time).

\subsubsection{Workload Measurement of Child Health Management}

The surveillance data were limited to the home-visited newborn infants and health-managed children aged 0 to 6 years. For the newborn infants, the accepted home visit services were usually covered by the establishment of the health records and follow-up health management; the number of health records established for the newborn infants and the number of health-managed children aged 0 were both substituted by the number of newborn infants with home visits. The number of health managed children aged 1-2 years was estimated using the number of newborn infants with home visits in the last two years. The number of health managed children aged 3-6 years was then calculated by the health-managed children aged 0-6 years minus the estimated number of health managed children aged 0 and 1-2 years. Due to the lack of related data, the workload of high-risk infants and children with nutritional diseases was not considered. The following formula was used to obtain the workload of maternal health management:

Workload of maternal health management $=$ the number of newborn infants with home visits $\times$ (3/person $+0.5 /$ person $)+$ (the number of newborn infants with home visit $\times 4$ times + the number of newborn infants with home visits in last the two years $\times 2$ times) $\times 2.5 /$ person-time + (the number of 
health managed children aged 0 to 6 years - the number of newborn infants with home visit - the number of newborn infants with home visit in last two years) $\times 2 /$ person.

\subsubsection{Workload Measurement of Children's Immunization}

There are 12 national immunization program vaccines totaling 22 doses provided for children aged 0 to 6 that are free of charge, 14 doses for primary vaccination (mainly targeting newborn infants), and eight doses for booster vaccination. The immunization information system data provided the numbers of the target children and immunized children of each vaccine included in the National Immunization Program in China. As each child must present their immunization certificate before vaccination, the number of new vaccination certificates in a certain year was substituted by the highest dose of vaccine of primary vaccination in the same year. Therefore, the workload of children's immunization = the highest dose of vaccines in primary vaccination $\times 0.5 /$ person + the total doses of vaccines included in the National Immunization Program $\times 1.5 /$ dose.

\section{Results}

\subsection{Change in the Birth Population in Zhejiang Province from 2014 to 2018}

From 2014 to 2018, the number of births from the Statistical Yearbook in Zhejiang Province were $578,000,581,000,624,000,670,000$, and 628,000 , respectively. The surveillance data were $416,941,41,490$, $434,163,546,816$, and 45,964 , respectively. The proportion of surveillance data in the yearbook data was $72.14 \%, 71.34 \%, 69.58 \%, 81.61 \%$, and $71.81 \%$, respectively.

The Statistical Yearbook and surveillance data showed a similar trend. The number of births in 2014 and 2015 were at the same low level, increased in 2016, and reached a peak in 2017, before falling back to a little higher than the 2016 level in 2018. The birth peak of the surveillance data in 2017 was more obvious when compared with the data in 2014, where the Yearbook and surveillance data increased by $15.92 \%$ and $31.15 \%$, respectively, as shown in Figure 1.

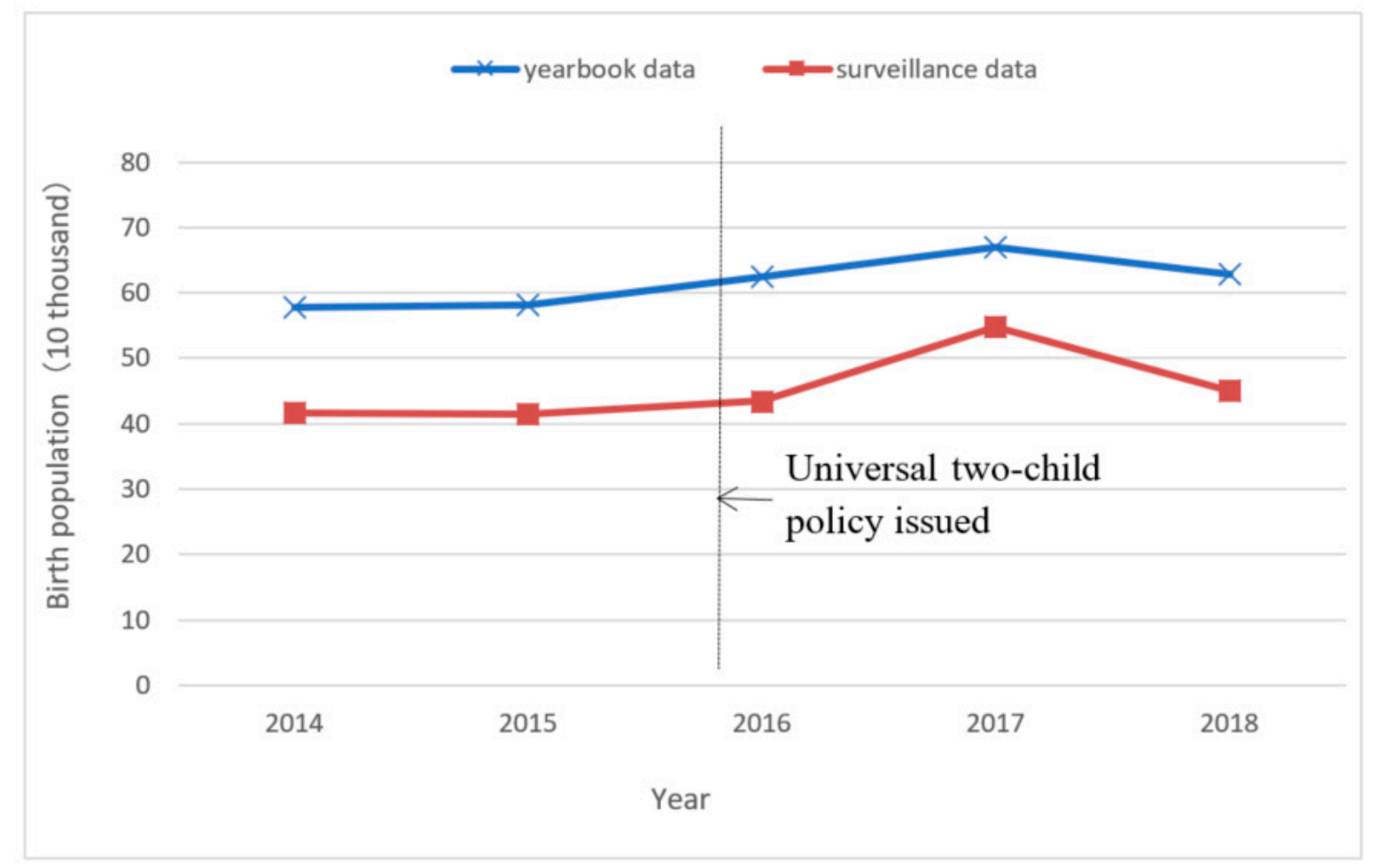

Figure 1. Comparison of the birth population data from different sources in Zhejiang Province, China, 2014-2018. 


\subsection{Impact of the Universal Two-Child Policy on Workload of Maternal Health Management}

The maternal health management indicators (early pregnancy registration rate and postpartum visit rate) stabilized at $96.22 \%$ to $98.08 \%$ in Zhejiang Province from 2014 to 2018 . The number of registered early pregnancies and postpartum visits increased by $30.50 \%$ and $30.74 \%$ in 2017, respectively, when compared with 2014. In 2018, the number of registered early pregnancies dropped to a level slightly higher than that in 2016, which was highly consistent with the trend in the number of births from the surveillance data.

The workload of maternal health management reached its peak in 2017, increasing by $30.37 \%$ over 2014 and falling in 2018, but still increased by 7.34\% over 2014, as shown in Table 2 and Figure 2.

Table 2. The workload of related community BPHS services in Zhejiang Province, 2014-2018.

\begin{tabular}{|c|c|c|c|c|c|c|}
\hline Categories & Indicator & 2014 & 2015 & 2016 & 2017 & 2018 \\
\hline \multirow{9}{*}{$\begin{array}{c}\text { Maternal } \\
\text { health } \\
\text { management }\end{array}$} & $\begin{array}{l}\text { Number of registered early } \\
\text { pregnancies (persons) }\end{array}$ & 403,979 & 402,569 & 422,091 & 527,202 & 433,913 \\
\hline & Early pregnancy registration rate $(\%)$ & 96.89 & 97.12 & 97.22 & 96.41 & 96.22 \\
\hline & $\begin{array}{l}\text { Number of prenatal examinations } \\
\text { (persons) }\end{array}$ & 402,011 & 399,066 & 418,175 & 522,407 & 429,830 \\
\hline & Prenatal examination rate (\%) & 96.42 & 96.28 & 96.32 & 95.54 & 95.31 \\
\hline & $\begin{array}{l}\text { Number of postpartum visits } \\
\text { (persons) }\end{array}$ & 407,483 & 404,712 & 425,833 & 532,726 & 439,277 \\
\hline & Postpartum visit rate (\%) & 97.73 & 97.64 & 98.08 & 97.42 & 97.41 \\
\hline & Workload & $7,273,830$ & $7,233,796$ & $7,589,110$ & $9,482,962$ & $7,807,392$ \\
\hline & $\begin{array}{l}\text { Workload change compared with } \\
\qquad 2014(\%)\end{array}$ & - & 99.45 & 104.33 & 130.37 & 107.34 \\
\hline & $\begin{array}{c}\text { Workload change compared with last } \\
\text { year }(\%)\end{array}$ & - & 99.45 & 104.91 & 124.95 & 82.33 \\
\hline \multirow{9}{*}{$\begin{array}{l}\text { Child health } \\
\text { management }\end{array}$} & $\begin{array}{l}\text { Number of newborn infants home } \\
\text { visited (persons) }\end{array}$ & 412,422 & 409,552 & 428,295 & 535,690 & 441,896 \\
\hline & $\begin{array}{l}\text { Home visit rate of newborn infant } \\
(\%)\end{array}$ & 98.92 & 98.81 & 98.65 & 97.97 & 97.99 \\
\hline & Children aged 0-6 years (persons) & $2,954,708$ & $2,877,405$ & $2,919,699$ & $3,135,183$ & $3,189,609$ \\
\hline & $\begin{array}{l}\text { Health managed Children aged 0-6 } \\
\text { years (persons) }\end{array}$ & $2,782,514$ & $2,832,300$ & $2,865,019$ & $3,046,490$ & $3,099,491$ \\
\hline & $\begin{array}{c}\text { Health management rate of Children } \\
\text { aged } 0-6 \text { years }(\%)\end{array}$ & 94.17 & 98.43 & 98.13 & 97.17 & 97.17 \\
\hline & $\begin{array}{l}\text { Estimation value of children aged } \\
1-2 \text { years (persons) }\end{array}$ & 818,150 & 811,316 & 821,974 & 837,847 & 963,985 \\
\hline & Workload & $8,177,737$ & $8,007,346$ & $8,195,021$ & $9,216,661$ & $8,809,646$ \\
\hline & $\begin{array}{l}\text { Workload change compared with } \\
\qquad 2014(\%)\end{array}$ & - & 97.92 & 100.21 & 112.70 & 107.73 \\
\hline & $\begin{array}{l}\text { Workload change compared with } \\
\text { previous year }(\%)\end{array}$ & - & 97.92 & 102.34 & 112.47 & 95.58 \\
\hline \multirow{5}{*}{$\begin{array}{l}\text { Children's } \\
\text { Immunization }\end{array}$} & $\begin{array}{l}\text { The highest dose of vaccines in } \\
\text { primary vaccination (persons) }\end{array}$ & 770,832 & 811,508 & 716,266 & 860,365 & 831,565 \\
\hline & Total doses (no.) & $16,063,652$ & $15,857,333$ & $15,492,062$ & $16,740,286$ & $15,849,757$ \\
\hline & Workload & $24,480,894$ & $24,191,754$ & $23,596,226$ & $25,540,612$ & $24,190,418$ \\
\hline & $\begin{array}{l}\text { Workload change compared with } \\
2014(\%)\end{array}$ & - & 98.82 & 96.39 & 104.33 & 98.81 \\
\hline & $\begin{array}{l}\text { Workload change compared with } \\
\text { previous year }(\%)\end{array}$ & - & 98.82 & 97.54 & 108.24 & 94.71 \\
\hline \multirow{3}{*}{ Total } & Workload & $39,932,461$ & $39,432,896$ & $39,380,357$ & $44,240,235$ & $40,807,456$ \\
\hline & $\begin{array}{l}\text { Workload change compared with } \\
\qquad 2014(\%)\end{array}$ & - & 98.75 & 98.62 & 110.79 & 102.19 \\
\hline & $\begin{array}{c}\text { Workload change compared with } \\
\text { previous year }(\%)\end{array}$ & - & 98.75 & 99.87 & 112.34 & 92.24 \\
\hline
\end{tabular}




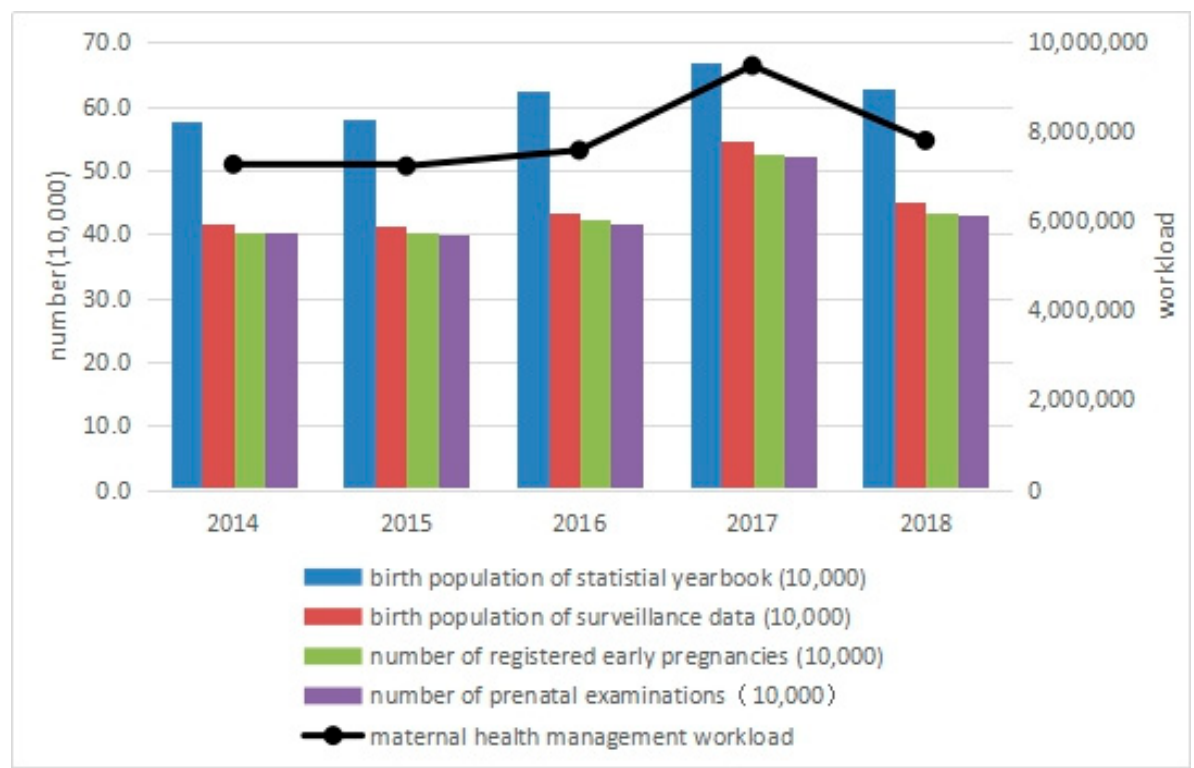

Figure 2. Maternal health management workload in Zhejiang Province, 2014-2018.

\subsection{Impact of the Universal Two-Child Policy on Child Health Management Workload}

Among the indicators of child health management in Zhejiang from 2014 to 2018, the rate of newborn home visits was stable between $97.97 \%$ and $98.92 \%$, and the rate of health management for children aged 0-6 fluctuated slightly between $94.17 \%$ and $98.43 \%$. The number of newborn home visits increased by $29.89 \%$ in 2017 when compared with that in 2014, and dropped to a level slightly higher than that in 2016 in 2018, which was highly consistent with the trend of the number of births in the surveillance data. The number of health-managed children aged 0-6 years increased by $9.89 \%$ in 2017 when compared with 2014, and continued to increase by $1.74 \%$ in 2018 .

The workload of child health management peaked in 2017, 12.70\% higher than that in 2014. Although it fell in 2018, it was still 7.73\% higher than that in 2014, as shown in Table 2 and Figure 3.

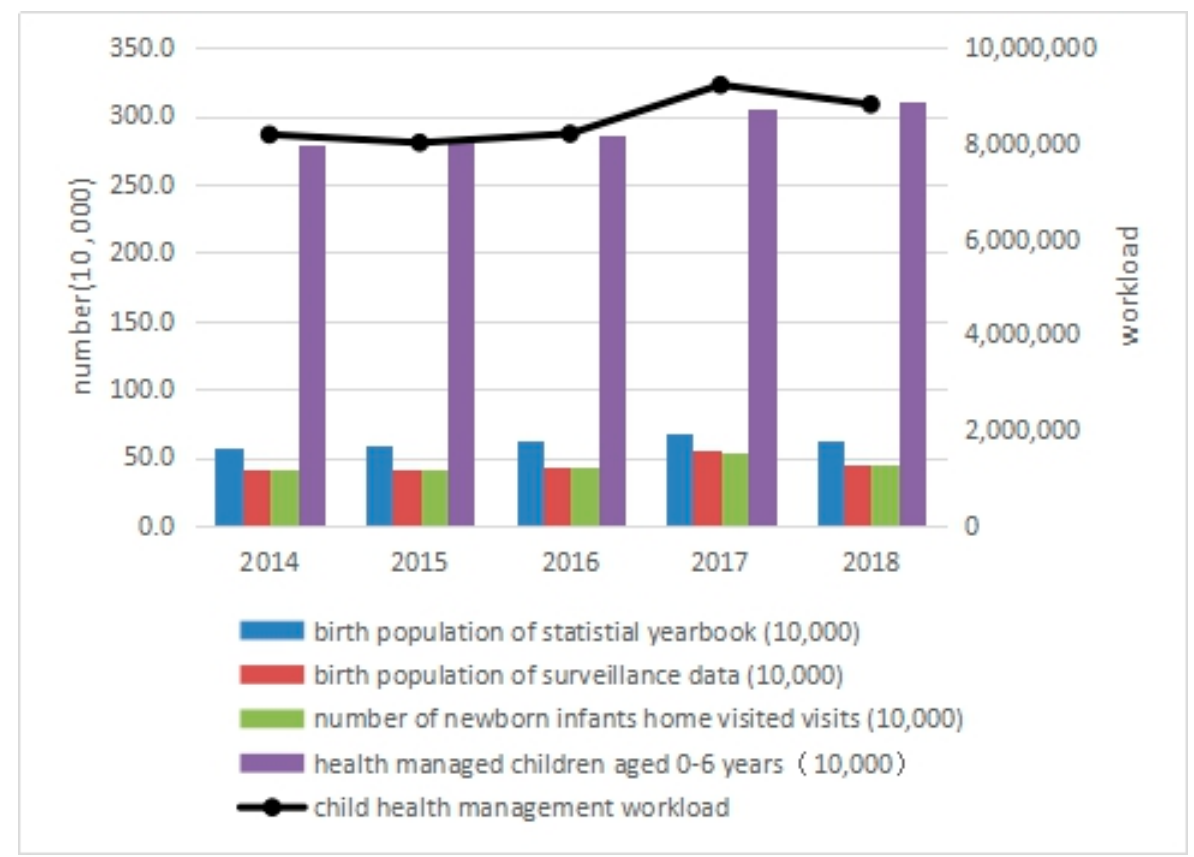

Figure 3. Child health management workload in Zhejiang Province, 2014-2018. 


\subsection{Impact of the Universal Two-Child Policy on Children's Immunization Workload}

From 2014 to 2018, the highest dose of primary vaccinations was significantly higher than the number of births in the same year. A peak appeared in 2017, but only increased by $11.61 \%$ when compared with 2014, which was lower than the increase in the number of births (even compared with the data from the Statistical Yearbook). The workload of immunization also peaked in 2017, with a small increase (4.33\% higher than that in 2014). In 2018, the workload fell back to $1.19 \%$ lower than in 2014, as shown in Table 2 and Figure 4.

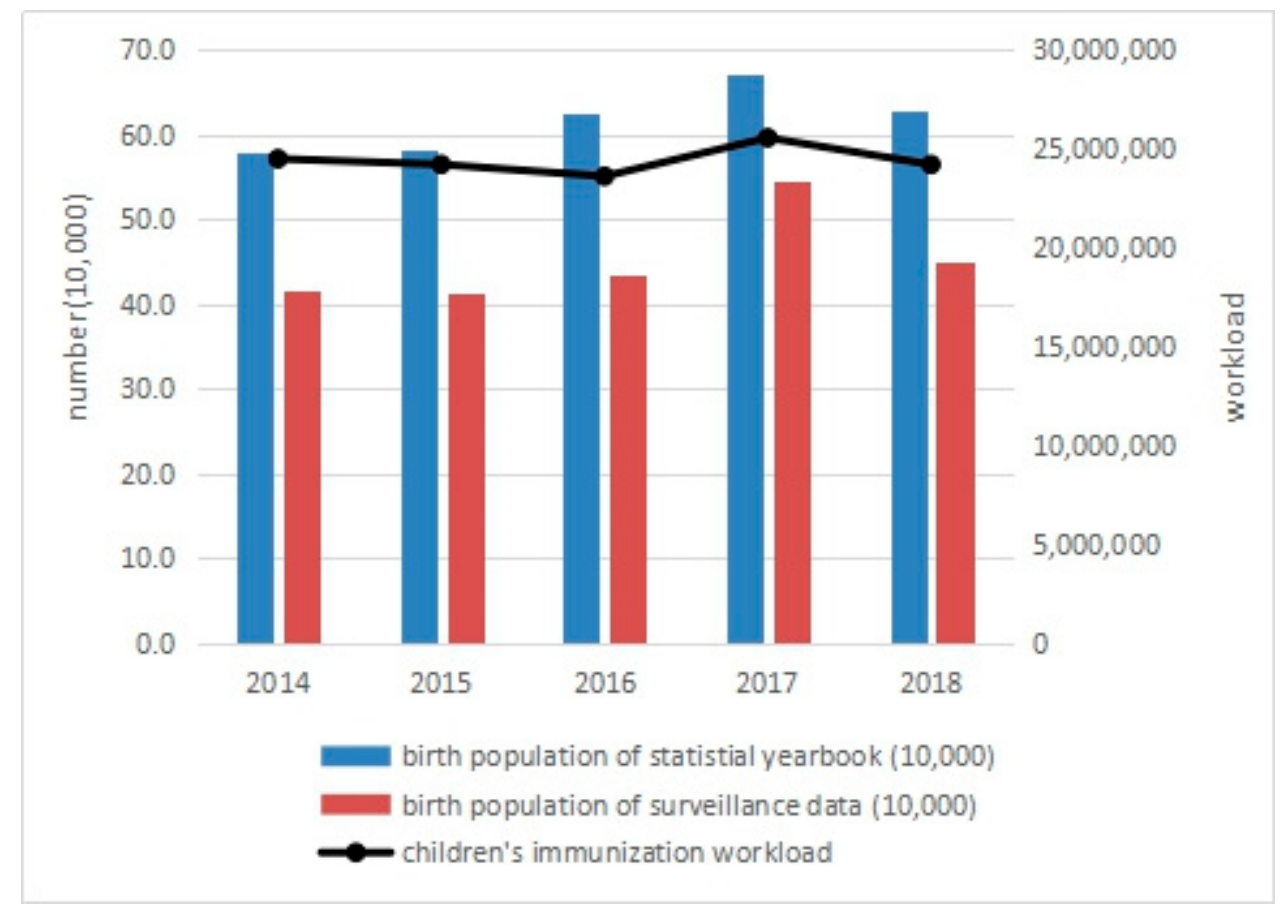

Figure 4. Children's immunization workload in Zhejiang Province, 2014-2018.

\section{Discussion}

After the implementation of the universal two-child policy, the birth peak in Zhejiang occurred in 2017, one year later than the national birth peak. The BPHS surveillance data showed a more obvious birth peak than the Statistical Yearbook data. Possible reasons for this are as follows: due to the release of prenatal demand suppressed by family planning policy, the proportion of women with high-risk pregnancies such as pregnant women older than 35 years or with a cesarean delivery history for their first birth, has increased significantly. This has resulted in continuously increasing incidences of pathological pregnancy, pregnancy complications, and a higher proportion of women with a scarred uterus who are pregnant again [9,24-26]; therefore, the willingness to seek prenatal examinations and other maternal health management services is stronger. Studies have shown that families with two children have a higher income [8], a higher awareness and acceptance of BPHS [27], and a higher likelihood of receiving maternal health management services. In addition, to implement the universal two-child policy, national publicity including free access to maternal health management has strengthened [28], which helps more pregnant women learn about and accept relevant services.

When compared with the number of births in the Statistical Yearbook, about 20-30\% of newborns were not covered by the BPHS from 2014 to 2018. However, during the peak birth rate in 2017, the coverage rate $(81.61 \%)$ was significantly higher than that in other years (69.58-72.14\%). The indicators of maternal and child health management and children's immunization services remained stable, and the related services did not decline, even in 2017. The number of births in the surveillance data was highly consistent with the number of early pregnancies, prenatal examinations, and newborn visits. This shows that as 
long as the newborns were covered by CHS, there was a high probability of the newborns and their mothers receiving systematic and continuous BPHS services.

We calculated the workload of related BPHS services (maternal and child health management and children's immunization) using the equivalent method, and analyzed the workload changes in Zhejiang Province from 2014 to 2018. The data showed that the workload of the related three BPHS services in 2017 (the peak births year) increased by 10.79\% when compared with that in 2014 (the universal two child policy had not yet been issued). The greatest impact was observed on maternal health management, which increased by $30.37 \%$ in 2017 , and the workload of child health management and children's immunization increased by $12.70 \%$ and $4.33 \%$, respectively. Regarding children's immunization, the increase in single primary vaccine administration was lower than that of births, even when compared with the data from the Statistical Yearbook. The possible reasons for this are as follows: the target children of immunization services in Zhejiang are those who have lived in Zhejiang for over three months, which covers more children than other BPHS services (target population lived there for over six months). One routine task involves conducting quarterly supplementary immunization to catch the children who have missed vaccinations, so the immunization service covers more migrant children than other BPHS services [29]. Primary vaccination targets not only include local and mobile newborns, but also any migrants aged over one year who missed their primary vaccinations. It also explains why the highest dose of vaccines in primary vaccination was significantly higher than the number of births in the Statistical Yearbook of the same year.

When the birth population fell in 2018, the maternal health management workload dropped simultaneously to $82.33 \%$ of the level of the previous year. Regarding child health management and children's immunization, the birth cohort in 2017 was still in the service age groups, so the decline was relatively small. If the number of births continues to decline in the next few years, the maternal health management workload will quickly fall back to an even lower level than the pre-universal-two-child era. However, the child health management workload will decline slowly for about three years, due to the higher EV of the health management of children aged 0-2 years than children aged 3-6 years. The factors influencing children's immunization workload are complex, except for the change in birth population, which is also affected by the size of the migrant population. In recent years, Zhejiang has continually attracted many immigrants, and the immunization workload will continue to be high.

\section{Conclusions}

The birth population of Zhejiang Province in China peaked in 2017 after the issuance of the universal two-child policy. The indicators of maternal and child health management and children's immunization services remained stable, and the related services did not decline, even in 2017. The implementation of the universal two-child policy has placed considerable but temporary pressure on maternal health care services, whereas the pressure on child health care services has been lower, but lasts longer. The factors influencing children's immunization are complex, and the direct impact of the universal two-child policy is relatively minimal.

\section{Limitations}

The limitation of this study was measuring the workload using limited surveillance data, especially given the lack of data on high-risk pregnancy women, high-risk children, and children with nutritional diseases. After the implementation of the universal two-child policy, the proportion of high-risk pregnancies increased significantly as above-mentioned, which also led to a corresponding increase in the incidence of high-risk infants such as premature births [30], coupled with the improvement in screening technology [31]. We did not include relevant work, and therefore underestimated the growth in the maternal and child health management workload.

Author Contributions: Y.Q. and J.L. were responsible for the study design and implementation. X.S., Q.Y. and W.W. took part in the surveillance data collection. Y.Z. was responsible for data analysis, paper writing and revision. All authors contributed to the discussion and interpretation of the data and to the writing of the manuscript. 
Funding: This research was funded by Medical Science and Technology Project of Zhejiang Province, China (grant number 2017KY296).

Conflicts of Interest: The authors declare no conflict of interest.

\section{References}

1. Zeng, Y.; Hesketh, T. The effects of China's universal two-child policy. Lancet 2016, 388, 1930-1938. [CrossRef]

2. Zheng, B. Population ageing and the impacts of the universal two-child policy on China's socio-economy. Econ. Political Stud. 2016, 4, 434-453. [CrossRef]

3. Padmadas, S.S. Two-child policy in China: Rhetoric versus reality. Ann. Hum. Biol. 2016, 1-2. [CrossRef] [PubMed]

4. Xu, L.; Yang, F.; Sun, J.; Nicholas, S.; Wang, J. Evaluating family planning organizations under China's two-child policy in Shandong Province. Int. J. Environ. Res. Public Health 2019, 16, 2121. [CrossRef] [PubMed]

5. Wang, L.; Xu, X.; Baker, P.; Tong, C.; Zhang, L.; Qi, H.; Zhao, Y. Patterns and associated factors of caesarean delivery intention among expectant mothers in China: Implications from the implementation of China's new national two-child policy. Int. J. Environ. Res. Public Health 2016, 13, 686. [CrossRef]

6. Zhao, J.; Shan, N.; Yang, X.; Li, Q.; Xia, Y.; Zhang, H.; Qi, H. Effect of second child intent on delivery mode after Chinese two child policy implementation: A cross sectional and prospective observational study of nulliparous women in Chongqing. BMJ Open 2017, 7, e018823. [CrossRef] [PubMed]

7. Wang, E.; Hesketh, T. Large reductions in cesarean delivery rates in China: A qualitative study on delivery decision-making in the era of the two-child policy. BMC Pregnancy Childbirth 2017, 17, 405. [CrossRef] [PubMed]

8. Zeng, C.; Yang, M.; Ding, Y.; Duan, S.; Zhou, Y. Placenta accreta spectrum disorder trends in the context of the universal two-child policy in China and the risk of hysterectomy. Int. J. Gynecol. Obstet. 2018, 140, 312-318. [CrossRef] [PubMed]

9. Li, Q.; Deng, D. New medical risks affecting obstetrics after implementation of the two-child policy in China. Front. Med. 2017, 11, 570-575. [CrossRef] [PubMed]

10. Zhang, X.Y.; Gao, Y.; Li, C.P.; Zheng, R.X.; Chen, J.L.; Zhao, L.; Wang, Y.G. Observed and projected trends in paediatric health resources and services in China between 2003 and 2030: A time-series study. BMJ Open 2017, 7, e015000. [CrossRef] [PubMed]

11. Song, Q.; Wang, F.; Song, L.; Zhuang, N.; Qiu, J.; Wang, L.; Yao, N. The pediatrician demands and gaps under the universal two-child policy. Chin. J. Health Policy 2015, 9, 65-70. (In Chinese)

12. Yang, T.; Wang, F.; Song, L.; Zhuang, N.; Qiu, J.; Wang, L.; Yao, N. The maternity beds demands and gaps under the universal two-child policy. Chin. J. Health Policy 2016, 9, 59-64. (In Chinese)

13. Yip, W.C.; Hsiao, W.C.; Chen, W.; Hu, S.; Ma, J.; Maynard, A. Early appraisal of China's huge and complex health-care reforms. Lancet 2012, 379, 833-842. [CrossRef]

14. Yang, L.; Sun, L.; Wen, L.; Zhang, H.; Li, C.; Hanson, K.; Fang, H. Financing strategies to improve essential public health equalization and its effects in China. Int. J. Equity Health 2016, 15, 194. [CrossRef] [PubMed]

15. Zhou, C. History of New China's population policy (6) relaxation of family planning policy priority transition of population work (2013). Popul. Soc. 2018, 6, 2. (In Chinese)

16. National Bureau of Statistics. Li xiru: Steady Population Growth and Gradual Improvement of Urbanization [EB/OL]. Available online: http://www.stats.gov.cn/tjsj/sjjd/201901/t20190123_1646380.html (accessed on 19 February 2019). (In Chinese)

17. Lancet, T. The two-child policy in China: What to expect? Lancet 2013, 382, 1758. [CrossRef]

18. Xia, S. Technical Report on Disease Prevention and Control in Zhejiang Province in 2014; Zhejiang Science and Technology Press: Hangzhou, China, 2015. (In Chinese)

19. Xia, S. Technical Report on Disease Prevention and Control in Zhejiang Province in 2015; Zhejiang Science and Technology Press: Hangzhou, China, 2016. (In Chinese)

20. Xia, S. Technical Report on Disease Prevention and Control in Zhejiang Province in 2016; Zhejiang Science and Technology Press: Hangzhou, China, 2017. (In Chinese)

21. Xia, S. Technical Report on Disease Prevention and Control in Zhejiang Province in 2017; Zhejiang Science and Technology Press: Hangzhou, China, 2018. (In Chinese) 
22. Hu, C. Technical Report on Disease Prevention and Control in Zhejiang Province in 2018; Zhejiang Science and Technology Press: Hangzhou, China, 2019. (In Chinese)

23. Yin, D.; Wong, S.T.; Chen, W.; Xin, Q.; Wang, L.; Cui, M.; Yin, T.; Li, R.; Zheng, X.; Yang, H. A model to estimate the cost of the national essential public health services package in Beijing, China. BMC Health Serv. Res. 2015, 15, 222. [CrossRef]

24. Liao, Z.; Zhou, Y.; Li, H.; Wang, C.; Chen, D.; Liu, J. The rates and medical necessity of cesarean delivery in the era of the two-child policy in Hubei and Gansu provinces, China. Am. J. Public Health 2019, 109, 476-482. [CrossRef]

25. Zhang, H.X.; Zhao, Y.Y.; Wang, Y.Q. Analysis of the characteristics of pregnancy and delivery before and after implementation of the two-child policy. Chin. Med. J. 2018, 131, 37-42. [CrossRef]

26. Fuchs, F.; Monet, B.; Ducruet, T.; Chaillet, N.; Audibert, F. Effect of maternal age on the risk of preterm birth: A large cohort study. PLoS ONE 2018, 13, e0191002. [CrossRef]

27. Shang, X.; Ye, C.; Yang, Q.; Qiu, Y.; Zhao, Y.; Wang, W.; Xu, X. Survey on the awareness of basic public health services for residents in Zhejiang province. Prev. Med. 2017, 11, 1174-1177. (In Chinese)

28. Information Office of the State Council. The National Health and Family Planning Commission Held a Conference on the Progress of the Comprehensive Two-Child Policy [EB/OL]. Available online: http: //www.scio.gov.cn/xwfbh/gbwxwfbh/xwfbh/wsb (accessed on 22 January 2017). (In Chinese)

29. Hu, Y.; Chen, Y.; Liang, H.; Wang, Y. Routine vaccination coverage of children aged 1-7 years in Zhejiang province, China. Hum. Vaccines Immunother. 2018, 14, 2876-2883. [CrossRef]

30. Zhao, J.; Yang, N.; Gong, L.; Yang, H.; Kong, Y. Analysis on newborn status of preterm infants in Beijing from 2011 to 2016. Chin. J. Child Health Care 2018, 26, 100-102. (In Chinese)

31. Wang, D.; Dai, H. Analysis of monitoring results of neuropsychological development in children aged 0 1 years in Beijing dongcheng district from 2009 to 2016. Chin. J. Child Health Care 2019, 7, 800-802. (In Chinese)

(C) 2019 by the authors. Licensee MDPI, Basel, Switzerland. This article is an open access article distributed under the terms and conditions of the Creative Commons Attribution (CC BY) license (http://creativecommons.org/licenses/by/4.0/). 